\title{
Does large breast problem and macromastia surgery affect a woman's body image, depression level, sexual lıfe, and qualıty of lıfe? A prospective study
}

\author{
Saliha Dikmen ${ }^{1}$, Melike Dissiz²* (1)
}

\section{SUMMARY}

OBJECTIVE: This study was designed to evaluate the change in the body perception, sexual life, quality of life, and depression levels in women undergoing a reduction mammaplasty due to breast hypertrophy problem.

METHODS: This descriptive and comparative study was carried out prospectively with 34 women who were diagnosed with breast hypertrophy in a public hospital in the province of Kayseri between 1 April and 31 December 2019 and agreed to participate in the study. The data were collected via the self-reporting method using the Introductory Information Form prepared in line with the literature, Preoperative Data Collection Form, Postoperative Data Collection Form, Female Sexual Function Index (FSFI), Quality of Life Questionnaire, Body Perception Scale (BPS), and Beck Depression Inventory (BDI).

RESULTS: In the preoperative period, $97.1 \%$ of the women with breast hypertrophy reported health complaints related to breast hypertrophy, $91.2 \%$ need to take a shower frequently, $85.3 \%$ social problems like shame and stigma, $85.3 \%$ exercise intolerance, and $79.4 \%$ sense of dislike. It was determined that general health complaints of these women decreased in the postoperative third month and they obtained significantly high scores from the FSFI, BDI, BPS, and all subscales of the SF-36 Quality of Life Questionnaire, except from the mental subscale $(p<0.05)$.

CONCLUSIONS: It was observed that there were remarkable improvements in the mental, physical, social, and sexual areas of women with breast hypertrophy after the reduction mammaplasty.

KEYWORDS: Body perception. Depression. Reduction mammoplasty. Sexual behavior. Quality of life.

\section{INTRODUCTION}

Breast hypertrophy is a benign enlargement of breast caused by the hyperplasia of the hormone-sensitive breast tissue and glandular epithelial tissue. It is also considered an excessive overgrowth of breast ${ }^{1,2}$. Although the presence of factors such as genetic predisposition and oversensitivity to estrogen is mentioned in the etiology of breast hypertrophy, this issue remains a mystery ${ }^{2}$. Breast hypertrophy is a disease that is encountered frequently in clinics, affects women's life multidimensionally, impairs the quality of life, and has mentally, physically, and socially negative effects ${ }^{1-6}$.

On the other hand, it has been reported that breast hypertrophy is an important factor affecting the body perception and is associated with negative body image $e^{4,711}$. In addition,

\footnotetext{
${ }^{1}$ Health Science University, Ministry of Health Kayseri City Hospital - Kayseri, Turkey.

${ }^{2}$ Health Science University, Hamidiye Faculty of Nursing - Istanbul, Turkey.

*Corresponding author: melekd78@gmail.com

Conflicts of interest: the authors declare there is no conflicts of interest. Funding: none.

Received on August 22, 2021. Accepted on August 24, 2021.
} 
it has been stated that the increase in breast size in women is associated with depression level ${ }^{5}$. It has been asserted that conditions (such as being disliked, anxiety, body image dissatisfaction and health issues, being unable to find appropriate clothes, and participating in sportive activities) caused by large breasts or breast hypertrophy lead to a psychological breakdown in women ${ }^{5,12}$. Psychological impairments or health issues caused by breast hypertrophy may directly trigger sexual dysfunctions, thus leading to sexual anxiety and avoidance of sexual activity ${ }^{13,14}$.

The purpose of this study was to address the breast hypertrophy problem and reduction mammaplasty from the perspective of women's health and determine the effect of reduction mammaplasty on women's body perception, sexual life, quality of life, and depression levels.

\section{METHODS}

\section{Type of the study}

The study was designed and carried out prospectively as a descriptive and comparative study.

\section{Population and sample of the study}

The population of the study consisted of all women with the diagnosis of breast hypertrophy who underwent a reduction mammaplasty in the Plastic and Reconstructive Surgery Clinic of a public hospital in the province of Kayseri. In this clinic, the total number of patients per year is 14,387 and the number of women undergoing a reduction mammaplasty due to breast hypertrophy problem is 41 . The sample of the study consisted of 37 women who applied to the hospital between April 19, 2019, and December 30, 2019, were diagnosed with breast hypertrophy, were over the age of 18 , had no communication obstacle or identified heavy mental disorder, and agreed to participate in the study after being informed. In the follow-up process, three patients, who withdrew from the study willingly and could not be reached for the post-test, were excluded. Finally, only 34 women completed the study. Data were collected from women admitted to the hospital through face-to-face interviews before (on the first day before the surgery - first interview) and after (at the third month after the surgery - second interview) surgery.

\section{Data collection tools}

The data were collected using Preoperative (on the first day before the surgery - first interview) and Postoperative (at the third month after the surgery - second interview) Data Collection Forms, which were prepared by the researchers and contain questions about women's sociodemographic characteristics (such as age, marital status, marriage duration, and educational background), gynecological-obstetrical characteristics (such as gravidity, parity, the number of miscarriages, the number of abortions, and state of menopause), and breast hypertrophy. The SF-36 Quality of Life Questionnaire (SF-36) ${ }^{15,16}$, Female Sexual Function Index (FSFI) $)^{17,18}$, Beck Depression Inventory (BDI) ${ }^{19,20}$, and Body Perception Scale (BPS) ${ }^{21}$ were also used.

\section{SF-36 Quality of Life Questionnaire (SF-36)}

It has eight subscales and 36 questions, with score ranging from 0 to 100 . Higher score is directly proportional to the quality of life $\mathrm{e}^{15,16}$.

\section{Female Sexual Function Index (FSFI)}

The index has six subscales and 19 questions, with score ranging from 2 (minimum) to 36 (maximum). Higher score indicates a better sexual function ${ }^{17,18}$.

\section{Beck Depression Inventory (BDI)}

It is a four-point Likert scale comprising a total of 21 items. Higher total score indicates a higher depression severity ${ }^{19,20}$.

\section{Body Perception Scale (BPS)}

The score of this scale ranges from 40 to 200 . Higher scores are directly proportional to the degree of satisfaction ${ }^{21}$.

\section{Ethical Approval and Consent to Participate}

Before the study, permission (No. E.15211) was obtained from the ethics committee of the hospital where the study was conducted (IRB: 2020/25) and from the hospital administration. Prior to the interviews, the participants were informed about the purpose and method of the study and their oral consent was obtained.

\section{Data analysis}

The collected data were evaluated using the Statistical Package for Social Science for Windows, version 21.0, package program. Descriptive measurements of all the variables were calculated. Categorical data were compared using the chi-square test and Fisher's exact test. The dependent-sample Student's t test was used to compare the scores related to repeated measurements and the Mann-Whitney U test was used for comparison between two independent groups. The multiple regression analysis was performed to examine the correlation between one dependent variable and two or more independent variables. A p-value $<0.05$ was considered statistically significant. 


\section{RESULTS}

When examining the sociodemographic characteristics of the women participated in the study, it was determined that their mean age was $41.47 \pm 10.0$ years (min: 22 , max: 64 ), mean marriage duration was $18.26 \pm 10.70$ years (min: 3 , max: 45 ), and average body mass index (BMI) was $26.37 \pm 3.43$ (min: 20.93 , max: 35.38 ). Notably, $55.9 \%$ had a BMI of $\geq 25$. It was found that women had a large breast problem for an average of 13.55 \pm 6.95 (min: 3 , max: 25) years (Table 1). Of the women with breast hypertrophy problem, $91.2 \%$ frequently took a shower due to malodor and sweating, and $94.1 \%$ had to choose large size cloths due to breast hypertrophy. Also, $79.4 \%$ of the women thought that they were not liked by people and $11.8 \%$ were subjected to verbal abuse (by their partners). On the one hand, the vast majority of women $(85.3 \%)$ reported that they felt embarrassed because their breasts looked too big and that they had problems in their social lives. On the other hand, more than half of the women $(85.3 \%)$ stated that they experienced limitation of movement (such as not being able to run, not be able to walk fast, and not be able to jump) due to large breast problems.

In this study, it was determined that the women with breast hypertrophy problem obtained significantly higher scores from all subscales of the SF-36 Quality of Life Questionnaire, except for the mental subscale in the postoperative third month, compared to preoperative period $(\mathrm{p}<0.001$, Table 2$)$.

The mean scores of the FSFI and subscales, as well as those of desire, arousal, lubrication, orgasm, general satisfaction, pain, and FSFI, were found to increase significantly compared to the first day before surgery and at the third month after surgery $(\mathrm{p}<0.001$, Table 2$)$.

The preoperative BDI mean scores of the women who underwent a surgery due to breast hypertrophy problem were significantly higher compared to the postoperative third month $(\mathrm{p}<0.001$, Table 2).

There was a statistically significant difference between the BPS scores of the women in the first interview conducted in the preoperative period and the second interview conducted in the postoperative third month, and the postoperative BPS scores significantly increased $(\mathrm{p}<0.001$, Table 2$)$.

In the multivariate analysis, it was found that $32 \%$ of the variance of the FSFI in women with breast hypertrophy problem was associated with the SF-36 Quality of Life Questionnaire - role limitations due to physical problems (beta $=-0.008, \mathrm{p}<0.05$ ), duration of breast hypertrophy problem (beta $=0.25, \mathrm{p}<0.05$ ), and Body Perception Scale (beta $=0.007$, $\mathrm{p}<0.05$ ), which were the determinants for the sexual functions of women with breast hypertrophy problem (Table 3).

\section{DISCUSSION}

In this study, the women's mean age was $41.47 \pm 10.00$ years, which is compatible with the study by Emami and Sobhani ${ }^{13}$. Emami and Sobhani suggested that women undergoing a reduction mammaplasty have a variation in age ${ }^{13}$. Some research studies found that most of the women were married and this

Table 1. Comparison of the participants' characteristics related to marriage and sexual life in the preoperative (first day) and postoperative (third month) periods ( $n=30$ ).

\begin{tabular}{|c|c|c|c|c|c|c|}
\hline \multirow[t]{2}{*}{ Characteristics } & \multicolumn{2}{|c|}{$\begin{array}{l}\text { Preoperative (first } \\
\text { day, first interview) }\end{array}$} & \multicolumn{2}{|c|}{$\begin{array}{c}\text { Postoperative (third } \\
\text { month, second interview) }\end{array}$} & \multirow[t]{2}{*}{$\mathrm{t}$} & \multirow[t]{2}{*}{$p$} \\
\hline & \multicolumn{2}{|c|}{ Mean \pm SD } & \multicolumn{2}{|c|}{ Mean \pm SD } & & \\
\hline Number of sexual intercourses (week) & \multicolumn{2}{|c|}{$1.96 \pm 0.88$} & \multicolumn{2}{|c|}{$2.46 \pm 1.07$} & -3.330 & 0.002 \\
\hline & Number & $\%$ & Number & $\%$ & $\chi^{2}$ & $p$ \\
\hline \multicolumn{7}{|l|}{ Relationship status with the partner } \\
\hline Very good/good & 17 & 65.4 & 1 & 25.0 & \multirow{2}{*}{-} & \multirow{2}{*}{$0.274^{*}$} \\
\hline Medium & 9 & 34.6 & 3 & 75.0 & & \\
\hline \multicolumn{7}{|l|}{ Satisfaction with sexual life } \\
\hline Satisfied & 20 & 74.1 & 2 & 66.7 & \multirow{2}{*}{-} & \multirow{2}{*}{0.172} \\
\hline Dissatisfied & 7 & 25.9 & 1 & 33.3 & & \\
\hline \multicolumn{7}{|l|}{ Sexual problems } \\
\hline Available & 8 & 88.9 & 8 & 38.1 & \multirow{2}{*}{-} & \multirow{2}{*}{$1.000^{*}$} \\
\hline NA & 1 & 11.1 & 13 & 61.9 & & \\
\hline
\end{tabular}

*Fisher's exact test. 
Table 2. Comparison of the women's SF-36 Quality of Life Questionnaire, female sexual function index subscale beck depression inventory, and body perception scale total scores in the preoperative (first day) and postoperative (third month) periods.

\begin{tabular}{|c|c|c|c|c|}
\hline \multirow{2}{*}{$\begin{array}{l}\text { Scales } \\
\text { SF-36 Quality of Life Questionnaire } \\
(n=34)\end{array}$} & $\begin{array}{l}\text { Preoperative (first } \\
\text { day, first interview) }\end{array}$ & $\begin{array}{c}\text { Postoperative (third } \\
\text { month, second interview) }\end{array}$ & \multirow[t]{2}{*}{$\mathrm{t}$} & \multirow[t]{2}{*}{$p$} \\
\hline & Mean \pm SD & Mean \pm SD & & \\
\hline Physical functioning & $41.17 \pm 28.04$ & $81.25 \pm 26.69$ & -5.982 & $0.000^{*}$ \\
\hline Role limitations due to physical problems & $47.05 \pm 42.97$ & $94.11 \pm 23.88$ & -4.961 & $0.000^{*}$ \\
\hline Role limitations due to emotional problems & $51.96 \pm 43.57$ & $95.09 \pm 18.59$ & -5.216 & $0.000^{*}$ \\
\hline Vitality & $36.63 \pm 18.75$ & $64.43 \pm 23.40$ & -5.554 & $0.000^{*}$ \\
\hline Mental health & $60.47 \pm 27.76$ & $67.84 \pm 27.12$ & -1.530 & 0.135 \\
\hline Social functioning & $43.27 \pm 27.12$ & $81.17 \pm 26.02$ & -5.640 & $0.000^{*}$ \\
\hline General health & $43.11 \pm 24.39$ & $70.77 \pm 17.59$ & -5.594 & $0.000^{*}$ \\
\hline Pain & $49.01 \pm 26.53$ & $69.11 \pm 32.01$ & -2.822 & $0.000^{*}$ \\
\hline \multicolumn{5}{|l|}{$\mathrm{FSFI}(\mathrm{n}=30)^{\dagger}$} \\
\hline Desire & $2.27 \pm 1.16$ & $3.95 \pm 0.82$ & -5.092 & $0.000^{*}$ \\
\hline Arousal & $2.26 \pm 1.14$ & $4.24 \pm 0.91$ & -6.143 & $0.000^{*}$ \\
\hline Lubrication & $2.84 \pm 1.45$ & $4.91 \pm 0.80$ & -5.396 & $0.000^{*}$ \\
\hline Orgasm & $2.32 \pm 1.38$ & $4.57 \pm 0.92$ & -6.215 & $0.000^{*}$ \\
\hline General satisfaction & $2.53 \pm 1.29$ & $5.00 \pm 0.79$ & -5.082 & $0.000^{*}$ \\
\hline Pain & $4.89 \pm 1.40$ & $5.24 \pm 0.94$ & -3.387 & $0.002^{*}$ \\
\hline FSFI total & $17.12 \pm 6.29$ & $27.93 \pm 3.96$ & -6.806 & $0.000^{*}$ \\
\hline BDI $(n=34)$ & $19.23 \pm 9.07$ & $6.73 \pm 4.68$ & 8.735 & $0.000^{*}$ \\
\hline $\operatorname{BPS}(n=34)$ & $108.76 \pm 23.32$ & $165.75 \pm 22.46$ & -10.407 & $0.000^{*}$ \\
\hline
\end{tabular}

SF-36: Short Form-36; FSFI: Female Sexual Function Index; BDI: Beck Depression Inventory; BPS: Body Perception Scale. * ${ }^{*}<0.05$; ${ }^{\dagger}$ Sexually inactive people were excluded.

Table 3. Multiple regression analysis for the variables related to the women's female sexual function index scores ( $\mathrm{n}=30)^{\star}$

\begin{tabular}{|c|c|c|c|c|c|}
\hline Variables & B & $\begin{array}{l}\text { Standard } \\
\text { error }\end{array}$ & b & $\mathrm{t}$ & $\mathrm{p}$ \\
\hline Constant & 0.909 & 0.572 & & 1.588 & 0.125 \\
\hline $\begin{array}{l}\text { SF-36 Quality of Life Questionnaire- } \\
\text { Role limitations due to physical problems }\end{array}$ & -0.008 & 0.003 & -0.441 & -2.625 & $0.015^{\dagger}$ \\
\hline Duration of breast hypertrophy problem (year) & 0.025 & 0.010 & 0.371 & 2.394 & $0.024^{+}$ \\
\hline Body Perception Scale & 0.007 & 0.004 & 0.345 & 2.152 & $0.042^{\dagger}$ \\
\hline
\end{tabular}

*Sexually inactive people were excluded; ${ }^{\dagger} p<0.05$. Dependent variable: Female Sexual Function Index cutoff point. R: 0.411, adjusted R²: 0.317, F: 4.362, $\mathrm{p}=0.008$, Durbin Watson: 1.971 .

may be due to the fact that they wished to have a positive body perception and to be liked by their partner or spouse $\mathrm{e}^{22,23}$. In this study, it was determined that $55.9 \%$ of the participants had a BMI of $\geq 25$ and there are also similar results in the literature $e^{4,24}$.

Several studies reported that breast hypertrophy affects all dimensions of the quality of life negatively ${ }^{1,7,23}$. Çeber et al. ${ }^{1}$ revealed that the quality of life of women with symptomatic macromastia was affected positively in the postoperative period. In this study, it was determined that the women with breast hypertrophy problem had lower quality of life and increased self-care needs in the preoperative period. In the reevaluations conducted for these women in the postoperative third month, it was determined that the women had significantly higher scores from all subscales of the SF-36 Quality of Life Questionnaire, except for the mental subscale. 
In contrast, body perception affects women both psychosocially and psychosexually ${ }^{7}$. Recent studies stated that women with breast hypertrophy problem have lower self-respect ${ }^{4,5,10}$. Janik et al. ${ }^{3}$ reported that body image dissatisfaction was a great problem for women with breast hypertrophy and shame, depression, and anxiety were associated with weak body image. In a study on women with breast hypertrophy problem, Pérez-Panzano et al. ${ }^{4}$ determined that there were improvements in not only body satisfaction but also mental state of mind and social relations in the postoperative period. Brunetti et al. ${ }^{7}$ found that there were significant improvements in body perception in the postoperative period. Also in this study, the women stated that their body became more proportional and their breasts became more upright, and as a result they felt more attractive, perceived themselves "just like a woman," looked fitter, and had a positive self-respect and higher self-confidence. In the follow-up conducted with the women with breast hypertrophy problem using the body perception scale in the postoperative third month, it was determined that the women obtained higher scores and their body perception improved at a positive level. Female breasts are an important part of sexual activity and self-confidence, and breast hypertrophy causes women to have lower self-confidence, sexual anxiety, and psychosexual problems ${ }^{13}$. Singh and Losken ${ }^{25}$ reported that $80 \%$ of women with breast hypertrophy problem had sexual problems, felt shame, and disliked being touched on their breasts (by their partner). Likewise, in this study, the women indicated that they felt shame when changing clothes and stripping their breasts in front of their partner, wanted to hide their breasts, and had a sense of being disliked (79.4\%). More than half of the women (53.3\%) stated that they had sexual problems in the preoperative period. In this context, the studies revealed that during the interviews carried out with the women with breast hypertrophy after reduction mammaplasty, there were improvements in their psychosexual functions ${ }^{3,10,14}$. As a matter of fact, in this study it was also determined that there were significant improvements in sexual functions of the women with breast hypertrophy problem in the postoperative third month.

Nonproportional, heavy, and large breasts are an effective factor for the cause of intense depressive symptoms ${ }^{5,10}$. Young women and adolescents, for whom body perception is more important, are more inclined to showing depressive symptoms. It is suggested that breast hypertrophy problem affects the bilateral relations or social relations negatively as a result of serious mental exposures in young women and adolescents ${ }^{5,6,12}$. Indeed, it is indicated that breast hypertrophy problem leads to risk in some adolescents such as eating disorder, bulimia nervosa, obesity, intentional vomiting, laxative and diuretic drugs, and suicidal thought ${ }^{1,8,12,25}$. It is stressed that reduction mammaplasty reduces negative mental effects in women with breast hypertrophy problem and thus provides multidimensional improvements in the quality of life and sexual life ${ }^{12,14,23,24}$. Rogliani et al. ${ }^{12}$ stated that reduction mammaplasty made permanent positive improvements in the quality of life and body image of women having breast hypertrophy problem and undergoing a surgery and significantly developed psychological well-being by removing the breast weight and ptosis. In this study, it was determined that $26.5 \%$ of the women ate less to have smaller breasts, felt shame, had low self-confidence, and their depressive symptoms decreased during the follow-up conducted in the postoperative third month compared to preoperative condition, which is compatible with the results of the studies.

\section{CONCLUSIONS}

Finally, it was determined that the women with breast hypertrophy problem had lower scores from all subscales of the SF-36 Quality of Life Questionnaire in the preoperative period, had a lower body perception, had lower mean scores from the FSFI total and all subscales, and showed depressive symptoms according to the BDI. It was found that the participants obtained higher scores from the SF-36 Quality of Life Questionnaire in the postoperative third month, had a positive body perception, had a positive effect in their sexual functions according to the FSFI, and decreased depressive symptoms according to the BDI.

\section{ACKNOWLEDGMENTS}

The authors are responsible for the content of this article. The authors thank all the staff at the medical center where the study was conducted, as well as each woman who participated in the research. The article has not been sent to any other journal for publication.

\section{AUTHORS" CONTRIBUTIONS}

SC: Conceptualization, Formal analysis, Investigation, Methodology, Writing - original draft, Writing - review and editing. MD: Conceptualization, Data curation, Investigation, Methodology, Project administration, Writing - original draft, Writing - review and editing. 


\section{REFERENCES}

1. Çeber M, Yıldız T, Eren E, Malak, A. The effects of reduction mammaplasty on body perception, quality of life and depression in women with symptomatic macromastia. Int J Basic Clin Med. 2016;4(1):17-28. Available from: https://dergipark.org. tr/tr/download/article-file/225823

2. Cogliandro A, Barone M, Cassotta G, Tenna, S, Cagli, B, Persichetti P. Patient satisfaction and clinical outcomes following 414 breast reductions: application of BREAST-Q. Aesthetic Plast Surg. 2017;41(2):245-9. https://doi.org/ 10.1007/s00266016-0774-y

3. Janik PE, Charytonowicz D, Miszczyk J, Charytonowicz M. Female sexual function and sexual well-being before and after breast reduction: A Pilot Cross-sectional Study and Review of Literature. Ann Plast Surg. 2019;82(6):609-13. https://doi. org/10.1097/SAP.0000000000001742

4. Pérez-Panzano E, Gascón-Catalán A, Sousa-Domínguez R, Carrera-Lasfuentes P, García-Campayo J, Güemes-Sánchez A. Reduction mammaplasty improves levels of anxiety, depression and body image satisfaction in patients with symptomatic macromastia in the short and long term. J Psychosom Obstet Gynecol. 2017;38(4):268-75. https://doi.org/10.1080/0167 $482 X .2016 .1270936$

5. Yagmur C, Ak S, Engin MS, Yildirim K, Gumus M, Kucuker I, et al. Anxiety and depression conditions do not influence postoperative satisfaction in breast reduction patients. J Exp Clin Med. 2016;33(4):195-8. https://doi.org/10.5835/jecm. omu.33.04.003

6. Nuzzi LC, Firriolo JM, Pike CM, DiVasta AD, Labow BI. Complications and quality of life following reduction mammaplasty in adolescents and young women. Plast Reconstr Surg. 2019;144(3):572-81. https://doi.org/10.1097/ PRS.0000000000005907

7. Brunetti AP, Macedo LGRP, Cangussu LDR, Carvalho, GS. The influence of breast hypertrophy on quality of life in women: a comparison between two study groups. Australian Journal of Basic and Applied Sciences. 2016;10(18):207-13. Available from: http://www.ajbasweb.com/old/ajbas/2016/ December/207-213.pdf

8. Losee JE, Jiang S, Long DE, Kreipe RE, Caldwell EH, Serletti JM. Macromastia as an etiologic factor in bulimia nervosa: 10-year follow up after treatment with reduction mammaplasty. Ann Plast Surg. 2004;52(5):452-7; discussion 457. https://doi. org/10.1097/01.sap.0000123344.08286.3e

9. Güemes A, Pérez E, Sousa R, Gil, I, Valcarreres MP, Carrera P, et al. Quality of life and alleviation of symptoms after breast reduction for macromastia in obese patients: is surgery worth it? Aesthetic Plast Surg. 2016;40(1):62-70. https://doi. org/10.1007/s00266-015-0601-x

10. Lewin R, Lidén $M$, Lundberg J, Hansson E, Selvaggi G, Thorarinsson $A$, et al. Prospective evaluation of health after breast reduction surgery using the Breast-Q, Short-Form 36, breast-related symptoms questionnaire, and modified breast evaluation questionnaire. Ann Plast Surg. 2019;83(2):143-51. https://doi.org/10.1097/SAP.0000000000001849

11. Lapid O, Corion LUM, Smeulders MJCS, Swinkels JA, van der Horst CMAM. Evaluating the psychopathological profile of women undergoing reduction mammaplasty with the symptom checklist-90-revised. Aesthet Surg J. 2014;34(5):719-22. https://doi.org/10.1177/1090820x14530717

12. Rogliani M, Gentile P, Labardi L, Donfrancesco A, Cervelli V. Improvement of physical and psychological symptoms after breast reduction. J Plast Reconstr Aesthet Surg. 2009;62(12):1647-9. https://doi.org/10.1016/j.bjps.2008.06.067

13. Emami SA, Sobhani R. Impact of reduction mammaplasty on sexuality in patients with macromastia and their partners. J Plast Reconstr Aesthet Surg. 2016;69(10):1335-9. https://doi. org/10.1016/j.bjps.2016.07.018

14. Beraldo FNM, Veiga DF, Veiga-Filho J, Garcia ES, VilasBôas GS, Juliano Y, et al. Sexual function and depression outcomes among breast hypertrophy patients undergoing reduction mammoplasty: a randomized controlled trial. Ann Plast Surg. 2016;76(4):379-82. https://doi.org/10.1097/ SAP.0000000000000380

15. Ware Jr JE, Sherbourne CD. The MOS 36-item short-form health survey (SF-36). I. Conceptual framework and item selection. Med Care. 1992;30(6):473-83. PMID: 1593914

16. Koçyiğit $H$. Reliability and validity of the Turkish version of short form-36 (SF-36): a study in a group of patients will rheumatic diseases. Turk J Drugs Ther. 1999;12:102-6.

17. Rosen R, Brown C, Heiman J, Leiblum S, Meston C, Shabsigh R, et al. The Female Sexual Function Index (FSFI): a multidimensional self-report instrument for the assessment of female sexual function. J Sex Marital Ther. 2000;26(2):191-208. https://doi. org/10.1080/009262300278597

18. Aygin $D$, Aslan FE. The Turkish adaptation of the female sexual function index. Türkiye Klinikleri J Med Sci. 2005;25(3):393-9.

19. Beck AT, Ward CH, Mendelson M, Mock J, Erbaugh J. An inventory for measuring depression. Arch Gen Psychiatry. 1961;4(6):56171. https://doi.org/10.1001/archpsyc.1961.01710120031004

20. Hisli N. Validity and reliability of beck depression inventory for university students. Psikoloji Dergisi, 1989;23:3-13.

21. Secord PF, Jourard SM. The appraisal of body-cathexis: bodycathexis and the self. J Consult Psychol. 1953;17(5):343-7. https://doi.org/10.1037/h0060689

22. International Society of Aesthetic Plastic Surgery. Aesthetic/ cosmetic procedures. Performed in 2018. Available from: https://www.isaps.org/wp-content/uploads/2020/10/ISAPSGlobal-Survey-Results-2018-1.pdf

23. Faria $A L$, Santos TCMM, Nakamiti MCP, Nascimento EFA Neves P, Gonçalves MS, et al. Discomforts, complications and satisfactions of women after reduction mammaplasty. Rev Enferm UFPE on line. 2009;3(4):913-8. https://doi.org/10.5205/ reuol.581-3802-1-RV.0304200916

24. Hernanz F, Fidalgo M, Muñoz P, González Noriega M, Gómez-Fleitas M. Impact of reduction mammoplasty on the quality of life of obese patients suffering from symptomatic macromastia: a descriptive cohort study. J Plast Reconstr Aesthet Surg. 2016;69(8):e168-73. https://doi.org/10.1016/j. bjps.2016.05.012

25. Singh KA, Losken A. Additional benefits of reduction mammoplasty: a systematic review of the literature. Plast Reconstr Surg. 2012;129(3):562-70. https://doi.org/10.1097/ PRS.0b013e31824129ee 